\title{
The Change in Self-Esteem among Middle School Students in Japan, 1989-2002
}

\author{
Yuji Ogihara1,2 \\ ${ }^{1}$ Department of Cognitive Psychology in Education, Graduate School of Education, Kyoto University, Kyoto, Japan \\ ${ }^{2}$ Japan Society for the Promotion of Science, Tokyo, Japan \\ Email: ogihara.yuji.3w@kyoto-u.ac.jp
}

How to cite this paper: Ogihara, Y. (2016). The Change in Self-Esteem among Middle School Students in Japan, 1989-2002. Psychology, 7, 1343-1351.

http://dx.doi.org/10.4236/psych.2016.711136

Received: June 3, 2016

Accepted: October 18, 2016

Published: October 21, 2016

Copyright $\odot 2016$ by author and Scientific Research Publishing Inc. This work is licensed under the Creative Commons Attribution International License (CC BY 4.0).

http://creativecommons.org/licenses/by/4.0/

\begin{abstract}
This paper examined temporal changes in self-esteem among middle school students in Japan from 1989 to 2002. Previous research showed that self-esteem decreased among middle school students between 1999 and 2006. However, it was unclear whether such a decrease was also present in other periods of time. To obtain a better understanding of how people adapt to socio-economic environments, it is important to gain a more comprehensive view of such long-term cultural/social changes. Therefore, to supplement the findings of the existing research on changes in self-esteem, we analyzed large-sample time-series data collected in Japan in 1989 and 2002. We found that middle schoolers' self-esteem decreased from 1989 to 2002, consistent with previous research. Thus, our study extends the previous research by presenting additional data showing the decrease in self-esteem in Japan.
\end{abstract}

\section{Keywords}

Self-Esteem, Temporal Change, Cultural Change, Social Change, Japan

\section{Introduction}

People adapt to temporal changes in socio-cultural environments. Thus, by examining how psychological tendencies and socio-cultural environments have changed over time, we can better understand how people adapt to socio-cultural environments (e.g., Greenfield, 2016; Twenge, 2015).

In the current research, we focus on self-esteem, which is an important psychological concept (e.g., Ogihara, 2016a). Self-esteem is one of the most frequently researched topics in psychology presumably because it is one of the most basic and important psychological concepts. Definitions of self-esteem vary across scientists, but a common aspect is that it refers to the positivity of a person's global evaluations of the self (e.g., 
Baumeister, Campbell, Krueger, \& Vohs, 2003). Self-esteem is closely related to psychological/physical health (e.g., Baumeister et al., 2003) and socio-economic status (e.g., Twenge \& Campbell, 2002). It also works as a signal of social standing, which encourages adaptive behaviors (e.g., Leary, Tambor, Terdal, \& Downs, 1995).

\subsection{Temporal Changes in Self-Esteem in the U.S.}

Twenge \& Campbell (2001) conducted a cross-temporal meta-analysis of scores from the Rosenberg Self-Esteem Scale (RSES; 1965) and Coopersmith Self-Esteem Inventory (Coopersmith, 1967). They showed that self-esteem increased among college students between 1968 and 1994, and among children and early adolescents between 1980 and 1993. In addition, they indicated that for children, these changes were positively associated with having comfortable socio-economic situation (e.g., negatively correlated with unemployment and divorce rates).

Gentile, Twenge, \& Campbell (2010) also conducted a cross-temporal meta-analysis on RSES scores (Rosenberg, 1965) between 1988 and 2008. They indicated that self-esteem increased among middle school, high school and college students over this time.

However, little research has investigated temporal changes in self-esteem in cultures outside the European American cultural context. To present a more general theory, it is necessary to examine other cultures as well. Therefore, we examined temporal changes in self-esteem in Japan.

\subsection{Temporal Changes in Self-Esteem in Japan}

In Japan, Oshio, Okada, Mogaki, Namikawa, \& Wakita (2014) conducted a crosstemporal meta-analysis on the scores of the RSES (Rosenberg, 1965) between 1984 and 2010. They found that self-esteem decreased among middle and high school students (analyzed together), college students and adults (aged 18 to 60, excluding college students).

Yet, their research 1) did not examine self-esteem at developmental stages prior to middle school, 2) did not separate middle schoolers from high schoolers in their analysis, and 3) analyzed data from samples that might not be representative of Japan as a whole. Therefore, Ogihara, Uchida, \& Kusumi (2016a) examined temporal changes in the self-esteem of elementary and middle school students separately between 1999 and 2006 by analyzing highly representative large-sample time-series data. They found that self-esteem decreased among both groups from 1999 to 2006, regardless of gender.

These findings are thought-provoking because at first glance, they appear to contradict previous literature. It has been suggested that Japanese culture has become more individualistic at least in some respects (Hamamura, 2012; Ogihara, 2016b; Ogihara, Fujita, Tominaga, Ishigaki, Kashimoto, Takahashi, Toyohara, \& Uchida, 2015; Ogihara, Uchida, Kusumi, 2015). Given this, it could be expected that self-esteem would have increased because self-esteem and individualistic tendencies are positively correlated (e.g., Heine, Lehman, Markus, \& Kitayama, 1999; Singelis, Bond, Sharkey, \& Lai, 1999). Indeed, that is the case in the U.S. where self-esteem has risen (e.g., Gentile et al., 2010; 
Twenge \& Campbell, 2001) as the culture has become more individualistic (e.g., DeWall, Pond Jr., Campbell, \& Twenge, 2011; Greenfield, 2013; Twenge, Abebe, \& Campbell, 2010; Twenge, Campbell, \& Gentile, 2012, 2013). Thus, while Japanese people should show increased self-esteem, it has actually decreased. This may be because Japanese culture has not been individualistic either historically or traditionally. Rather, it has undergone a rapid change towards greater individualism, which might have caused conflicts and difficulties in adapting to it (Ogihara \& Uchida, 2014; Ogihara, Uchida \& Kusumi, 2014).

However, it is unclear whether similar decreases in self-esteem occurred during other periods of time. To comprehensively understand cultural changes, it is desirable to examine long-term cultural changes (e.g., Grossmann \& Varnum, 2015; Mesoudi, 2011). Thus, it is necessary to examine cultural changes in other periods of time and integrate them into the accumulated findings.

\subsection{Present Study}

The current research examined temporal changes in self-esteem among middle school students in Japan from 1989 to 2002 by analyzing large-sample time-series data. We predicted that self-esteem would decrease from 1989 to 2002, consistent with previous research (Ogihara et al., 2016a, 2016b; Oshio et al., 2014).

\section{Method}

\subsection{Data}

We analyzed data that was collected by the Japan Youth Research Institute in 1989 and 2002 (JYRI; Japan Youth Research Institute, 1990, 2002). Data was collected to be proportionate with the types of schools (public:private $=5: 1$ ) and types of areas (urban:rural $=6: 5)$ in middle schools in Japan for both 1989 and 2002. Sample sites were 11 (1989 sample) and 12 (2002 sample) schools in 10 prefectures (similar to states in the U.S.). The distributions for all answers for each item were published by the JYRI (raw data at the individual level was not available, nor were results by gender or school grade).

\subsection{Respondents}

The sample sizes were 1288 (male: 50.2\%, female: 48.9\%, unknown 0.9\%) in 1989 and 1071 (male: $46.8 \%$, female: 52.6\%, unknown 0.7\%) in 2002. There was no significant difference in the gender ratio between two surveys, $\chi^{2}(2)=3.54, p=0.17$. In the 2002 survey, a greater proportion of participants were 2 nd-year students and a lower proportion were 3rd-year students compared to the 1989 survey (1989, 1st-year: 31.9\%, 2ndyear: 33.8\%, 3rd-year: 34.3\%; 2002, 1st-year: 30.1\%, 2nd-year: 44.2\%, 3rd-year: 25.8\%; $\left.\chi^{2}(2)=31.08, p<0.001\right)$. The students answered paper questionnaires in the classes.

\subsection{Question Items}

Eight items from the RSES (Rosenberg, 1965) were used to measure self-esteem (see 
Table 1). Four items were affirmative measures and four items were negative (i.e., reverse-coded). Respondents answered to what extent each sentence applied to them on a 4-point scale (1: applies very much, 2: applies somewhat, 3: does not apply much, 4: does not apply at all). For ease of interpretation, we reversed the scores and subtracted 1 (i.e., 3: applies very much, 2: applies somewhat, 1: does not apply much, 0 : does not apply at all).

\section{Results}

A summary of the results is shown in Table 1.

\subsection{Positive Items}

Consistent with our hypothesis, the average scores for three items were lower in 2002 than in 1989. Yet, one item showed no change.

\subsection{Negative Items}

Consistent with our prediction, self-evaluations on two items were more negative in 2002. But, self-evaluations for the other two items grew less negative.

\section{Discussion}

\subsection{Summary of the Results}

This study examined how self-esteem changed for Japanese middle schoolers between 1989 and 2002. Previous research showed that self-esteem decreased between 1999 and 2006 (Ogihara et al., 2016a). However, it was unclear whether such decreases occurred during other periods of time. It is important to examine long-term cultural/social changes (e.g., Grossmann \& Varnum, 2015; Mesoudi, 2011). Therefore, we analyzed large-sample time-series data collected in 1989 and 2002. Results showed that selfesteem generally decreased among middle school students. But, some items initially

Table 1. Temporal changes in self-esteem among middle school students between 1989 and 2002.

\begin{tabular}{lllllll}
\hline \multicolumn{1}{c}{ Item } & \multicolumn{1}{c}{$M_{1989}(S D)$} & $M_{2002}(S D)$ & $t$ & $d_{2002-1989}$ \\
\hline Positive & 1 & On the whole, I am satisfied with myself. & $1.39(0.93)$ & $1.22(0.91)$ & $4.31^{* *}$ & -0.18 \\
& 2 & I feel that I have a number of good qualities. & $1.32(0.83)$ & $1.25(0.81)$ & $2.14^{*}$ & -0.09 \\
& 3 & $\begin{array}{l}\text { I am able to do things as well as most other } \\
\text { people. }\end{array}$ & $1.64(0.89)$ & $1.61(0.89)$ & 0.84 & -0.03 \\
& & $\begin{array}{l}\text { I feel that I'm a person of worth, at least on an } \\
\text { equal plane with others. }\end{array}$ & $1.26(0.84)$ & $1.26(0.81)$ & 0.06 & 0.00 \\
Negative & 1 & I certainly feel useless at times. & $1.56(0.88)$ & $1.63(0.94)$ & $-1.77+$ & 0.07 \\
& 2 & I feel I do not have much to be proud of. & $1.47(0.87)$ & $1.48(0.92)$ & -0.22 & 0.01 \\
& 3 & I wish I could have more respect for myself. & $1.85(0.88)$ & $1.81(0.87)$ & 1.12 & -0.05 \\
& 4 & At times I think I am no good at all. & $1.12(0.94)$ & $1.10(0.85)$ & 0.72 & -0.03 \\
\hline
\end{tabular}

Note: ${ }^{* *} p<0.001,{ }^{*} p<0.05,+p<0.10$. 
seemed inconsistent.

Two negative items showed a pattern that was opposite to the other items. Previous research has showed that the item ("I wish I could have more respect for myself") is often dropped from analyses due to weak correlations with other items, implying low validity and reliability (e.g., Abe \& Konno, 2007; Ito \& Kodama, 2005; Moroi, 1985). Indeed, among studies in Oshio et al.'s (2014) meta-analysis, this item was most frequently removed from analysis (in 18 of the 19 studies reporting dropped items ${ }^{1}$ ). Further, the JYRI used the Japanese word “jisonshin (自尊心; self-esteem)” in this item, but it is probably not so common for Japanese, especially for middle schoolers. JYRI also used the word "rakugosya (落伍者; one who is a failure)" in the item (“At times I think I am no good at all”). These words are not commonly used by middle schoolers, which might decrease the validity and reliability of these items. Indeed, these two words are not used in the most frequently used Japanese translations of the RSES (Hoshino, 1970; Sakurai, 2000; Yamamoto, Matsui, \& Yamanari, 1982). Therefore, we do not think that the results from these two negative items were sufficiently valid or reliable.

In addition, one positive item ("I feel that I'm a person of worth, at least on an equal plane with others") indicated no change between the 1989 and 2002. This was possibly due to item wording. This item and another item showing a small change ("I am able to do things as well as most other people") explicitly ask respondents to engage in social comparisons. People from different groups use different referents when evaluating themselves, which obscures real differences (the reference-group effect; e.g., Heine, Lehman, Peng, \& Greenholtz, 2002). So even if the average level of self-evaluation decreased from 1989 to 2002, self-evaluations based on social comparison may show little or no difference. While people generally use social comparison to evaluate themselves in questionnaires, when social comparisons are emphasized, the reference group effect should be stronger. Thus, it is understandable to find little or no difference in these items.

Another point that needs to be addressed is that of respondent grade-level proportion differences in the two surveys, which might have affected the decrease in selfesteem. Specifically, there was a greater proportion of 2nd-year students and a lower proportion of 3rd-year students in the 2002 survey than in the 1989 survey. However, previous research has indicated that average self-esteem levels are higher in 2nd-year students than in 3rd-year students, regardless of gender (e.g., Cabinet Office Government of Japan, 2000). Therefore, the decrease was unlikely to be caused by these differences. Rather, it is reasonable to think that the difference would be somewhat larger if the grade-level ratio was controlled between the two surveys.

In conclusion, we suggest that self-esteem decreased between 1989 and 2002 among middle school students, which is consistent with previous findings (Ogihara et al. 2016a; Oshio et al., 2014). Our research extends the existing literature by showing that ${ }^{1}$ The second most frequently dropped item is "I take a positive attitude toward myself" (dropped in three studies), but this item was not used in this research. Other dropped items are "All in all, I am inclined to feel that I am a failure" (not used in this research) and "On the whole, I am satisfied with myself", but each was dropped in only one study out of the 19 studies reporting dropped items. 
self-esteem declined in Japan for a period of time outside that of 1999 to 2006 . Because of the importance of examining long-term cultural/social changes (e.g., Grossmann \& Varnum, 2015; Mesoudi, 2011), these findings are valuable. Given that Japanese culture has become more individualistic in some respects (Hamamura, 2012; Ogihara, 2016b; Ogihara, Fujita et al., 2015; Ogihara, Uchida, \& Kusumi, 2015), findings that indicate concurrent decreases in self-esteem are important additions to the literature.

\subsection{Limitations and Future Directions}

One might be skeptical about the conclusion that self-esteem decreased over this period since it is based on data from two points in time, which might be exceptional for some reason (e.g., substantial social events). This lack of additional time points is due to the difficulties of obtaining old archival data in Japan compared to in the U.S. (e.g., Ogihara, 2015; Ogihara, Fujita et al., 2015). However, previous research has shown that levels of self-esteem in 1989 and 2002 are not outliers compared to other years (Ogihara et al., 2016b; Oshio et al., 2014), so our conclusion is not diminished by this limitation. Yet, it would be ideal to examine temporal changes in self-esteem with more sequential datasets.

While our evidence shows that self-esteem decreased from 1989 to 2002, it is unclear why this happened. It is necessary to investigate this issue in the future. However, identifying the decrease in self-esteem levels is an important first step.

\section{Acknowledgements}

I thank Pamela Taylor for her helpful comments on earlier versions of the manuscript. I would also like to express my appreciation to Yumi Inoue for her cooperation in obtaining archival data. This research was partially supported by Yukiko Uchida at the Kokoro Research Center, Kyoto University and the Japanese Group Dynamics Association.

\section{References}

Abe, M., \& Konno, H. (2007). Development of State Self-Esteem Scale. The Japanese Journal of Personality, 16, 36-46. https://www.jstage.jst.go.jp/article/personality/16/1/16_1_36/_article

Baumeister, R. F., Campbell, J. D., Krueger, J. I., \& Vohs, K. D. (2003). Does High Self-Esteem Cause Better Performance, Interpersonal Success, Happiness, or Healthier Lifestyles? Psychological Science in the Public Interest, 4, 1-44. http://dx.doi.org/10.1111/1529-1006.01431

Cabinet Office, Government of Japan (2000). Survey of the Values of Young Adolescents in Japan. http://www8.cao.go.jp/youth/kenkyu/teinenrei/html/html/mokuji.html

Coopersmith, S. (1967). The Antecedents of Self-Esteem. New York: Freeman.

DeWall, C. N., Pond Jr., R. S., Campbell, W. K., \& Twenge, J. M. (2011). Tuning in to Psychological Change: Linguistic Markers of Psychological Traits and Emotions over Time in Popular US Song Lyrics. Psychology of Aesthetics, Creativity, and the Arts, 5, 200-207. http://dx.doi.org/10.1037/a0023195

Gentile, B., Twenge, J. M., \& Campbell, W. K. (2010). Birth Cohort Differences in Self-Esteem, 1988-2008: A Cross-Temporal Meta-Analysis. Review of General Psychology, 14, 261-268. 
http://dx.doi.org/10.1037/a0019919

Greenfield, P. M. (2013). The Changing Psychology of Culture from 1800 through 2000. Psychological Science, 24, 1722-1731. http://dx.doi.org/10.1177/0956797613479387

Greenfield, P. M. (2016). Social Change, Cultural Evolution, and Human Development. Current Opinion in Psychology, 8, 84-92. http://dx.doi.org/10.1016/j.copsyc.2015.10.012

Grossmann, I., \& Varnum, M. E. (2015). Social Structure, Infectious Diseases, Disasters, Secularism, and Cultural Change in America. Psychological Science, 26, 311-324. http://dx.doi.org/10.1177/0956797614563765

Hamamura, T. (2012). Are Cultures Becoming Individualistic? A Cross-Temporal Comparison of Individualism-Collectivism in the United States and Japan. Personality and Social Psychology Review, 16, 3-24. http://dx.doi.org/10.1177/1088868311411587

Heine, S. J., Lehman, D. R., Markus, H. R., \& Kitayama, S. (1999). Is There a Universal Need for Positive self-Regard? Psychological Review, 106, 766-794. http://dx.doi.org/10.1037/0033-295X.106.4.766

Heine, S. J., Lehman, D. R., Peng, K., \& Greenholtz, J. (2002). What's Wrong with Cross-Cultural Comparisons of Subjective Likert Scales? The Reference-Group Effect. Journal of Personality and Social Psychology, 82, 903-918. http://dx.doi.org/10.1037/0022-3514.82.6.903

Hoshino, A. (1970). Psychology of Emotion and Education. Child Psychology, 24, 1445-1477.

Ito, M., \& Kodama, M. (2005). Sense of Authenticity, Self-Esteem, and Subjective and Psychological Well-Being. Japanese Journal of Educational Psychology, 53, 74-85.

https://www.jstage.jst.go.jp/article/jjep1953/53/1/53_74/_article

Japan Youth Research Institute (1990). Report of the Survey on the Lifestyles of Middle School Students: Predictions for the Future (a Comparison of Japan, the U.S., and China).

Japan Youth Research Institute (2002). Report of the Survey on the Lifestyles and Values of Middle School Students (a Comparison of Japan, the U.S., and China).

Leary, M. R., Tambor, E. S., Terdal, S. K., \& Downs, D. L. (1995). Self-Esteem as an Interpersonal Monitor: The Sociometer Hypothesis. Journal of Personality and Social Psychology, 68, 518530. http://dx.doi.org/10.1037/0022-3514.68.3.518

Mesoudi, A. (2011). Cultural Evolution: How Darwinian Theory Can Explain Human Culture and Synthesize the Social Sciences. Chicago, IL: University of Chicago Press. http://dx.doi.org/10.7208/chicago/9780226520452.001.0001

Moroi, K. (1985). Loneliness and Self-Consciousness in High-School Students. Japanese Journal of Psychology, 56, 237-240.

https://www.jstage.jst.go.jp/article/jjpsy1926/56/4/56_4_237/_article

Ogihara, Y. (2015). Characteristics and Patterns of Uncommon Names in Present-Day Japan. Journal of Human Environmental Studies, 13, 177-183. https://www.jstage.jst.go.jp/article/shes/13/2/13_177/_article

Ogihara, Y. (2016a). Age Differences in Self-Liking in Japan: The Developmental Trajectory of Self-Esteem from Elementary School to Old Age. Letters on Evolutionary Behavioral Science, 7, 33-36. http://dx.doi.org/10.5178/lebs.2016.48

Ogihara, Y. (2016b). Are Common Names Becoming Less Usual in Japan? An Analysis of Baby Names from 30 Years of City Newsletters, 1984-2015. Poster session presented at the 12th Cultural Psychology Preconference (at the 17th Annual Meeting of Society for Personality and Social Psychology), San Diego, California, January 2016.

Ogihara, Y., Fujita, H., Tominaga, H., Ishigaki, S., Kashimoto, T., Takahashi, A., Toyohara, K., \& Uchida, Y. (2015). Are Common Names Becoming Less Common? The Rise in Uniqueness 
and Individualism in Japan. Frontiers in Psychology, 6, 1490.

http://dx.doi.org/10.3389/fpsyg.2015.01490

Ogihara, Y., \& Uchida, Y. (2014). Does Individualism Bring Happiness? Negative Effects of Individualism on Interpersonal Relationships and Happiness. Frontiers in Psychology, 5, 135.

http://dx.doi.org/10.3389/fpsyg.2014.00135

Ogihara, Y., Uchida, Y., \& Kusumi, T. (2014). How Do Japanese Perceive Individualism? Examination of the Meaning of Individualism in Japan. Psychologia: An International Journal of Psychological Sciences, 57, 213-223. https://www.jstage.jst.go.jp/article/psysoc/57/3/57_213/_article

Ogihara, Y., Uchida, Y., \& Kusumi, T. (2015). Are People Giving More Unique Names to Their Dogs? Rising Uniqueness and Individualism in Japan. Paper Session Presented at the 62nd Annual Meeting of Japanese Group Dynamics Association, Nara, Japan, October 2015.

Ogihara, Y., Uchida, Y., \& Kusumi, T. (2016a). Losing Confidence over Time: Temporal Changes in Self-Esteem among Older Children and Early Adolescents in Japan, 1999-2006. SAGE Open, 6, 1-8. http://dx.doi.org/10.1177/2158244016666606

Ogihara, Y., Uchida, Y., \& Kusumi, T. (2016b). Losing Confidence over Time: Temporal Changes in Self-Esteem in Japan. Poster Session Presented at the 17th Annual Meeting of Society for Personality and Social Psychology, San Diego, California, January 2016.

Oshio, A., Okada, R., Mogaki, M., Namikawa, T., \& Wakita, T. (2014). Age and Survey-Year Effects on Self-Esteem in Japan: A Cross-Temporal Meta-Analysis of Scores on Rosenberg's SelfEsteem Scale. Japanese Journal of Educational Psychology, 62, 273-282. https://www.jstage.jst.go.jp/article/jjep/62/4/62_273/_article

Rosenberg, M. (1965). Society and the Adolescent Self-Image. Princeton, NJ: Princeton University Press. http://dx.doi.org/10.1515/9781400876136

Sakurai, S. (2000). Investigation of the Japanese Version of Rosenberg's Self-Esteem Scale. Bulletin of Tsukuba Developmental and Clinical Psychology, 12, 65-71.

Singelis, T. M., Bond, M. H., Sharkey, W. F., \& Lai, C. S. Y. (1999). Unpackaging Culture’s Influence on Self-Esteem and Embarrassability the Role of Self-Construals. Journal of CrossCultural Psychology, 30, 315-341. http://dx.doi.org/10.1177/0022022199030003003

Twenge, J. M. (2015). The Age in Which We Live and Its Impact on the Person. In K. J. Reynolds, \& N. R. Branscombe (Eds.), Psychology of Change: Life Contexts, Experiences, and Identities (pp. 44-58). New York: Psychology Press.

Twenge, J. M., Abebe, E. M., \& Campbell, W. K. (2010). Fitting in or Standing Out: Trends in American Parents' Choices for Children's Names, 1880-2007. Social Psychological and Personality Science, 1, 19-25. http://dx.doi.org/10.1177/1948550609349515

Twenge, J. M., \& Campbell, W. K. (2001). Age and Birth Cohort Differences in Self-Esteem: A Cross-Temporal Meta-Analysis. Personality and Social Psychology Review, 5, 321-344. http://dx.doi.org/10.1207/S15327957PSPR0504_3

Twenge, J. M., \& Campbell, W. K. (2002). Self-Esteem and Socioeconomic Status: A Meta-Analytic Review. Personality and Social Psychology Review, 6, 59-71. http://dx.doi.org/10.1207/S15327957PSPR0601_3

Twenge, J. M., Campbell, W. K., \& Gentile, B. (2012). Increases in Individualistic Words and Phrases in American Books, 1960-2008. PLoS ONE, 7, e40181. http://dx.doi.org/10.1371/journal.pone.0040181

Twenge, J. M., Campbell, W. K., \& Gentile, B. (2013). Changes in Pronoun Use in American Books and the Rise of Individualism, 1960-2008. Journal of Cross-Cultural Psychology, 44, 
406-415. http://dx.doi.org/10.1177/0022022112455100

Yamamoto, M., Matsui, Y., \& Yamanari, Y. (1982). The Structure of Perceived Aspects of Self. Japanese Journal of Educational Psychology, 30, 64-68.

https://www.jstage.jst.go.jp/article/jjep1953/30/1/30_64/_article

Submit or recommend next manuscript to SCIRP and we will provide best service for you:

Accepting pre-submission inquiries through Email, Facebook, LinkedIn, Twitter, etc. A wide selection of journals (inclusive of 9 subjects, more than 200 journals)

Providing 24-hour high-quality service

User-friendly online submission system

Fair and swift peer-review system

Efficient typesetting and proofreading procedure

Display of the result of downloads and visits, as well as the number of cited articles

Maximum dissemination of your research work

Submit your manuscript at: http://papersubmission.scirp.org/

Or contact psych@scirp.org 